\title{
The Nonlinear Single Controller of DGEN380 Aero Engine Design
}

\author{
Jie Bai $\mathbb{D}^{1,2}$ Shuai Liu ${ }^{1},{ }^{1}$ and Wang Wei ${ }^{2}$ \\ ${ }^{1}$ School of Mechanical Engineering, Hebei University of Technology, Tianjin 300130, China \\ ${ }^{2}$ Key Laboratory for Civil Airworthiness Certification Technology, Civil Aviation University of China, Tianjin 300300, China
}

Correspondence should be addressed to Shuai Liu; caucliushuai@163.com

Received 15 October 2018; Revised 18 March 2019; Accepted 22 May 2019; Published 2 July 2019

Academic Editor: Antonio Concilio

Copyright (C) 2019 Jie Bai et al. This is an open access article distributed under the Creative Commons Attribution License, which permits unrestricted use, distribution, and reproduction in any medium, provided the original work is properly cited.

\begin{abstract}
The advanced nonlinear sliding mode control method of DGEN380 aero engine is presented in this paper. This aero engine is a small high bypass ratio turbofan engine by which the nonlinear control approach of the aero engine is invested. And this paper focuses on the power management function of the aero engine control system which includes steady control and transient control. The mathematical model of DGEN380 aero engine is built by a set of nonlinear dynamic equation that is validated by experimental data. The single controller based on sliding mode approach is designed that can keep some certain thrust levels during steady state and maintain repeatable performance during transient operation from one requested thrust level to another. The single controller can offset the impact of the signal noise and harmonic disturbance at a certain power point. And the dynamic performance of the single controller is satisfactory at the transient process. The experiment is conducted by aero engine test bench for the single control.
\end{abstract}

\section{Introduction}

A new configuration of the small aero engine, DGEN380 aero engine, is presented in this research. The DGEN380 aero engine which is a turbofan engine has been designed to motorize private flight aircraft. The DGEN380 aero engine constitutes the core of the family of high bypass ratio engines with a thrust ranging from $2.5 \mathrm{kN}$ to $4 \mathrm{kN}$. The DGEN380 aero engine is also modern and innovative in its geared architecture, even more so in its "all-electric" design for all the equipment around the engine, all the pumps of DGEN380 being not mechanically but electrically driven. Meanwhile, this aero engine can be used for the investment of the control approach. The advanced control approach of the aero engine is analyzed by the DGEN380 real engine test bench. And the advanced control approach may be embodied in the control of aero engine to the engine. So, the DGEN380 aero engine is regarded as a control object. Nonlinear control approach is concerned by DGEN380 real engine test bench.

There are two essential functions in the control system of the aero engine which are power management and limitation protection. And power management includes steady state control and transition state control [1]. However, the real controller of the aero engine consists of steady controller, transient controller, and limitation controller now. The proportional integral controller, the PI controller is widely used in the industrial field (including for aero engine), is used for steady state control. The gain scheduling approach bases on multi-PI controller what has applied in aero engine transient controller now. These controllers correspond to different states. The switching strategy is necessary to whose function is to select the corresponding controller. And this controller structure has many disadvantages [2], which is not apt to the need of advanced control method, so the application of nonlinear control technology in the aero engine control field is reasonable. The power management of the aero engine control method is the focus of attention in this research. The single controller is different from the traditional controller which is composed of steady controller and transient controller. To design a single controller which can keep some certain thrust levels during steady state and maintain repeatable performance during transient operation from one requested thrust level to another, this paper analyzes an advanced nonlinear control method.

Some nonlinear control methods have been used to overcome the disadvantages of robustness and a limited operating 


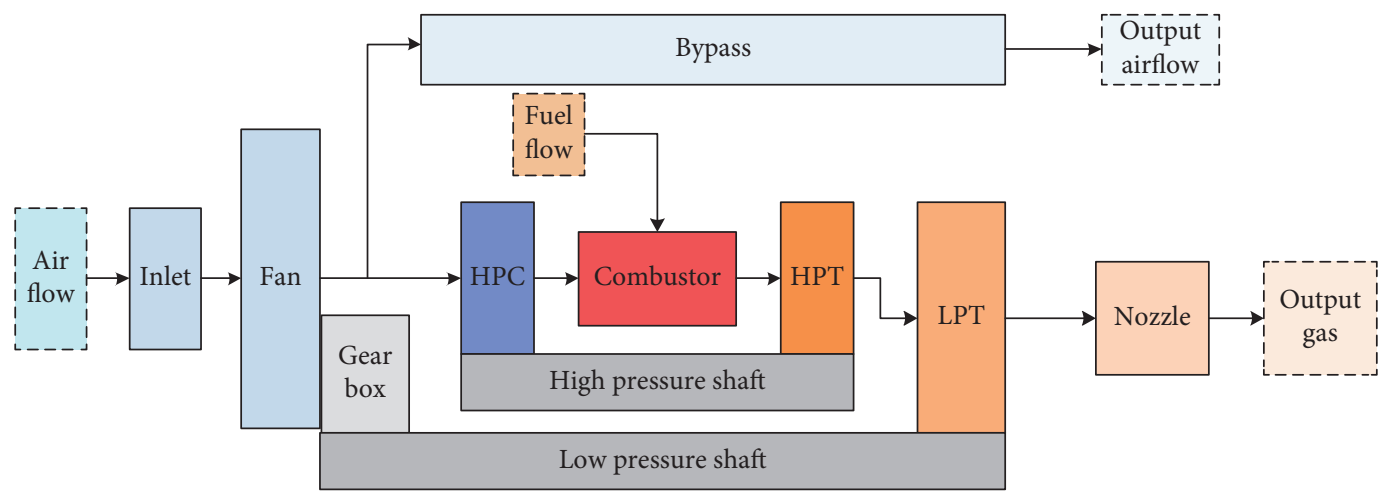

FIGURE 1: Schematic configuration of DGEN380 aero engine.

domain such as fuzzy sliding mode control, adaptive neural network, and integral sliding mode control [3]. The choice of this research has been to develop a sliding mode control method, which is known to be robust versus parametric uncertainties and has been used in numerous industrial applications including wind turbines area.

The purpose of this research is then to propose that a nonlinear control approach for DGEN380 aero engine is to implement the power management of the aero engine. The main achievements are the nonlinear model of DGEN380 aero engine and the advanced nonlinear controller which both can be used for steady control and transient control [4-9].

In this paper, the mathematical model of DGEN380 aero engine is built, and the control scheme based on the nonlinear model is designed by the sliding mode control method. In Section 2, the nonlinear model of DGEN380 aero engine is introduced. This section includes the establishment DGEN380 model and the validation of the model. And the control problem is stated in Section 3. Then, a sliding model control scheme of power management of aero engine is detailed in Section 4, which also includes the discussion of simulation results and experimental results. And conclusions and future work are presented in Section 5.

\section{Model of DGEN380 Aero Engine}

The structure of DGEN380 aero engine is generally similar to a general turbofan engine. There are two (or three) shafts in the aero engine. And they are low pressure rotor and high pressure rotor. Figure 1 shows the structure diagram of DGEN380 aero engine which is produced by Price Induction company. The fan, gearbox, and the low pressure turbine are on the same low pressure shaft $\left(N_{1}\right)$. The high pressure compressor and the high pressure turbine are on the same high pressure shaft $\left(N_{2}\right)$ [1].

Since this research intends to design a controller based on aero engine model which can be competent in doing power management of an aero engine at the steady state and the transition state, the aero engine model should be able to capture the dynamic characteristic and steady characteristic of the aero engine in a broad flight envelope.

The differential equation is a useful way to establish the mapping relation between state variables and input variables. If the differential term equals zero, the steady state character- istic can be obtained. Nevertheless, if the differential term does not equal zero, the dynamic process is described. So, the two-shaft differential equations which simulate among the rotation processes of high pressure rotor and low pressure rotor and the one volume dynamic equation which concludes aerodynamic parameters variation and simultaneous equations are both developed in engine modeling [4].

The model neglects not only the ignition process but also the starting process and numerous physical features of the aero engine, such as reaction, diffusion, and fluid-structure interactions; all of them are ignored. But the adiabatic exponent is constant. This research ignores the heat exchange between high temperature gases and components.

2.1. Shaft Dynamic Model. The shaft dynamic equation, derived by Newton's second law, is proposed to describe the motion process of high pressure and low pressure shafts. Equation (1) is the shaft dynamic [4].

$$
J \frac{d \omega}{d t}=\Delta M=\left(M_{\mathrm{T}}-M_{\mathrm{C}}\right)
$$

where $\Delta M$ is the excess power, $M_{\mathrm{T}}$ is the turbine torque, $M_{\mathrm{C}}$ is compressor torque, $J$ is the moment of inertia of the high pressure shaft and low pressure shaft, and $\omega$ means the angular velocity of the shaft which is proportional to the shaft speed.

2.2. Combustion Dynamic Model. The volume dynamic equation can draw the aerodynamic parameters' (pressure and temperature variation) change at both the inlet and outlet of chambers, which is then used for combustor chamber modeling. Equation (2) is the volume dynamic [4].

$$
\rho V \frac{d u}{d t}+V u \frac{d \rho}{d t}=q_{m, \text { in }} h_{\text {in }}-q_{m, \text { out }} h_{\text {out }}
$$

where $V$ is the volume of the combustor chamber, $u$ and $\rho$ are the internal energy and density of working fluid of combustor, respectively, $q_{m}$ represents the flow rate, and $h$ is the enthalpy. 
The continuity equation can be expressed as

$$
V \frac{d \rho}{d t}=q_{m, \text { in }}-q_{m, \text { out }}
$$

where the corresponding relation of aerodynamic parameters of combustor is given.

The volume dynamic equation can be simplified by the continuity equation, which is written as

$$
\rho V \frac{d u}{d t}=q_{m, \text { in }} h_{\text {in }}-q_{m, \text { out }} h_{\text {out }}+q_{m, \text { out }} u-q_{m, \text { in }} u .
$$

2.3. Aero Engine Model. The DGEN380 engine model is built by low pressure rotor and high pressure rotor and a volume dynamic equation. The DGEN380 engine model can be written as a nonlinear system affine with respect to the engine input vector:

$$
\dot{\mathbf{x}}=f(\mathbf{x})+g(\mathbf{x}) \cdot \mathbf{u},
$$

with $\mathbf{x}$ is the state vector and $\mathbf{u}$ is the input vector, respectively, defined as follows:

$$
\begin{aligned}
& \mathbf{x}=\left[\begin{array}{lll}
n_{1} & n_{2} & T_{4}
\end{array}\right]^{T}, \\
& \mathbf{u}=\left[\begin{array}{ll}
W_{f}
\end{array}\right] .
\end{aligned}
$$

The vector $f(\mathbf{x})$ and the matrix $g(\mathbf{x})$ read as follows:

$$
\begin{aligned}
& f(\mathbf{x})= {\left[\begin{array}{c}
C_{1} \cdot \frac{1}{n_{1}} \cdot\left(W_{\mathrm{LPT}} \cdot q_{m, \mathrm{LPT}} \cdot \eta_{l m}-W_{\mathrm{Fan}} \cdot q_{m, \mathrm{Fan}}\right) \\
C_{2} \cdot \frac{1}{n_{2}} \cdot\left(W_{\mathrm{HPT}} \cdot q_{m, \mathrm{HPT}} \cdot \eta_{h m}-W_{\mathrm{HPC}} \cdot q_{m, \mathrm{HPC}}\right) \\
\frac{R \cdot T_{4} \cdot q_{m, \mathrm{in}}}{C_{V} \cdot P_{4} \cdot V} \cdot\left(C_{p}-C_{V}\right) \cdot\left(T_{3}-T_{4}\right)
\end{array}\right], } \\
& g(\mathbf{x})=\left[\begin{array}{c}
C_{1} \cdot \frac{1}{n_{1}} \cdot W_{\mathrm{LPT}} \cdot \eta_{l m} \\
C_{2} \cdot \frac{1}{n_{2}} \cdot W_{\mathrm{HPT}} \cdot \eta_{h m} \\
\frac{R \cdot T_{4}}{C_{V} \cdot P_{4} \cdot V} \cdot\left(C_{V}-C_{p}\right) \cdot T_{4}
\end{array}\right],
\end{aligned}
$$

where $C_{1}=(30 / \pi)^{2}\left(1 / J_{1}\right), C_{2}=(30 / \pi)^{2}\left(1 / J_{2}\right), W_{\text {Fan }}$ means the work consumed by the fan, $W_{\text {HPC }}$ means the work consumed by the high pressure compressor, $W_{\text {HPT }}$ means the work produced by the high pressure turbine, and $W_{\mathrm{LPT}}$ means the work produced by the low pressure turbine.

The consumed work or produced work can be obtained by system identification method. The relation equation identified by experimental data is written as follows:

$$
W=f\left(\frac{n_{i}}{\sqrt{T_{i}}}\right), \quad i=1,2,
$$

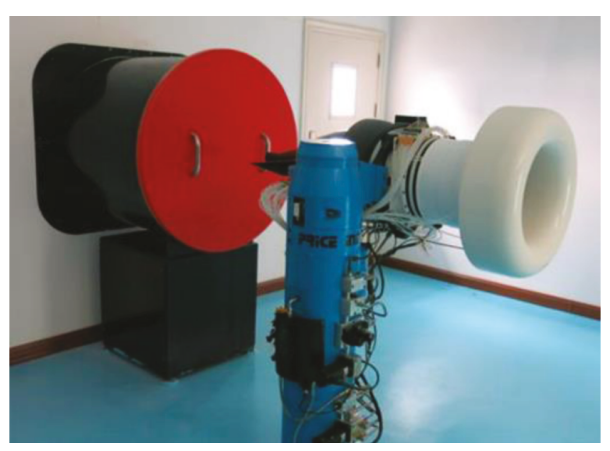

Figure 2: DGEN380 aero engine test bench.

where $n_{i}$ is the shaft speed and $W$ is the consumed work or produced work. Equation (8) sets relation between rotary parts and shaft speed. Least squares method is the identification tool of this study that is invoked in MATLAB tool box $[5,6]$. And the test data of rotary parts is obtained by test bench of DGEN380. Figure 2 pictured DGEN380 aero engine test bench. These four relation equations, $W_{\text {Fan }}=f\left(n_{1} / \sqrt{T}\right)$, $W_{\mathrm{HPC}}=f\left(n_{2} / \sqrt{T_{2}}\right), W_{\mathrm{HPT}}=f\left(n_{2} / \sqrt{T_{1}}\right)$, and $W_{\mathrm{LPT}}=f\left(n_{1} /\right.$ $\left.\sqrt{T_{1}}\right)$, are obtained by the identification method. Figure 3 shows the results of the identification of (8). The max error of identification is less than $1 \%$. In other words, the identification equations of rotary parts can be applied to the substitutes of components' characteristic of the compressor or turbine which can reduce the difficulty in control scheme design because the analysis formulations are obtained.

Equations (5)-(9) show that the DGEN380 engine model is established by dynamic differential equations which form is too simple. Because of the assumed condition, the partial differential equations' modeling reaction, diffusion, and fluid structure interactions do not exist. And the components' characteristic can convert to an analysis formulation. What is more, there are three state variables, $N_{1}, N_{2}$, and $T_{4}$, in the DGEN380 aero engine model which determined by aero engine theory, and other variables can be expressed as a linear or nonlinear combination of these three state variables.

2.4. Model Validation. Transient simulations and steady state simulations are implemented in the MATLAB commercial software that establishes a simulation environment. A variable-step implicit solver was designed to solve stiff problems, "ode15s," which was chosen as the time-stepping algorithm.

2.4.1. Steady Simulation Results. Table 1 lists the simulation results of the DGEN380 engine steady state using a numerical method (Figure 4). The effects of the steady state include idle power point, cruise power point, and climb power point. While the steady state point value was given manually, it is used for validating simulation results. The max error is $0.43 \%$. The result of steady state is accurate.

The approach presented in this paper can meet the target value. Comparing to that of traditional method, this approach has simpler formulations, more rapid convergence (as shown in Figure 4), and closer to a practical model as well as more convenient for programming. 


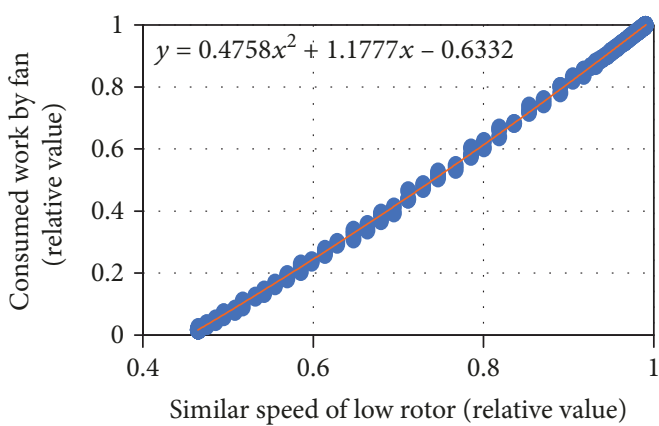

(a)

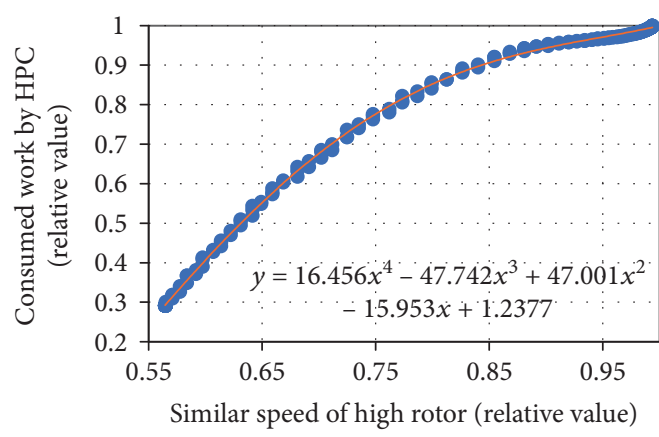

(c)

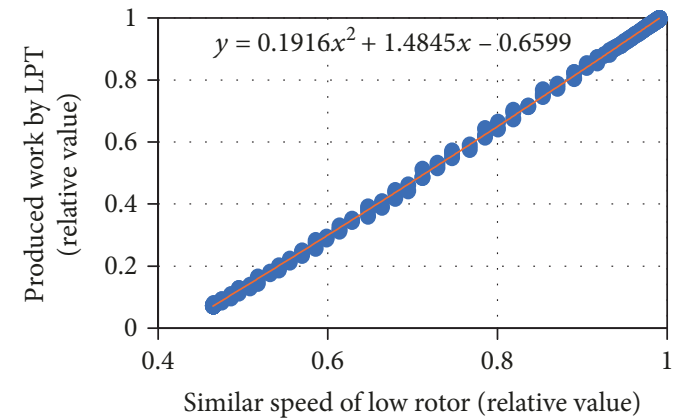

(b)

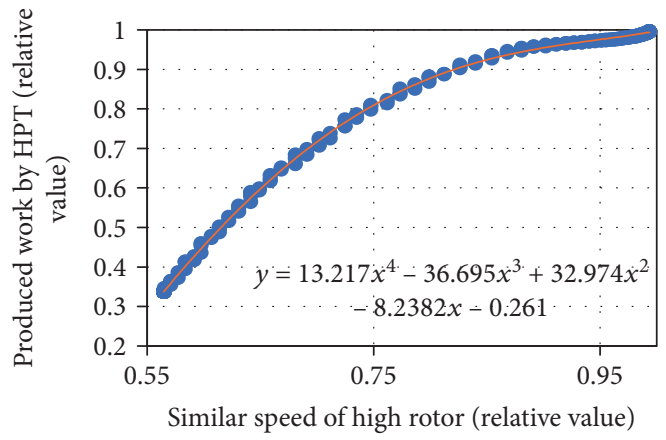

(d)

Figure 3: The results of the identification of mapping relation between the rotary. (a) The corresponding relation between the consumed work by fan and low rotor speed (spot-component test data, line-identification curve). (b) The corresponding relation between the produced work by LPT and low rotor speed (spot-component test data, line-identification curve). (c) The corresponding relation between the consumed work by HPC and high rotor speed (spot-component test data, line-identification curve). (d) The corresponding relation between the produced work by HPT and high rotor speed (spot-component test data, line-identification curve).

TABLE 1: Steady simulation results.

\begin{tabular}{lcccccccc}
\hline & $\begin{array}{c}\text { Manual } \\
\text { value }\end{array}$ & $\begin{array}{c}N_{1} \text { relative value } \\
\text { Simulation } \\
\text { result }\end{array}$ & $\begin{array}{c}\text { Error } \\
(\%)\end{array}$ & $\begin{array}{c}\text { Manual } \\
\text { value }\end{array}$ & $\begin{array}{c}N_{2} \text { relative value } \\
\text { Simulation } \\
\text { result }\end{array}$ & $\begin{array}{c}\text { Error } \\
(\%)\end{array}$ & $\begin{array}{c}\text { Manual } \\
\text { value }\end{array}$ & $\begin{array}{c}T_{4} \text { relative value } \\
\text { Simulation } \\
\text { result }\end{array}$ \\
\hline Idle & 0.4701 & 0.47006 & $\mathbf{0 . 0 0 9}$ & 0.5676 & 0.56761 & $\mathbf{0 . 0 0 2}$ & 0.6516 & 0.65154 \\
Cruise & 0.925 & 0.9251 & $\mathbf{0 . 0 1 1}$ & 0.9559 & 0.95594 & $\mathbf{0 . 0 0 4}$ & 0.939 & 0.93902 \\
Climb & 1 & 1.00043 & $\mathbf{0 . 0 4 3}$ & 1 & 1.00026 & $\mathbf{0 . 0 2 6}$ & 1 & $\mathbf{0 . 0 0 9}$ \\
\hline
\end{tabular}

2.4.2. Transition Simulation Results. The transition simulation describes the acceleration process and the deceleration process, that is, the acceleration (or deceleration) process starts from one set point to another, which combines a fuel schedule between them. The DGEN380 engine test is implemented to validate the dynamic characteristic of DGEN380 aero engine model. And the test results can provide accurate test data comparison with transient simulation computation results by the variable-step implicit solver. The acceleration/deceleration process of the test is the same with the process of simulation which includes two increasing procedures of shaft speed from the idle power to the climb power, a decreasing process from the climb power to the idle power, a decreasing process from the climb power to the cruise power, and a decreasing process from the cruise power to the idle power. The test results are displayed as the $N_{1}$ curve, $N_{2}$ curve, and $T_{4}$ curve in Figure 5. The max error is $2.77 \%$. The simulative traces demonstrate good agreement with the test trace during the acceleration process and deceleration process. Moreover, transient behavior shows good agreement.

A systems-level engine model, DGEN380 aero engine model, which form is simple to obtain is presented here. By solving a set of nonlinear dynamic equation, the solutions of steady state and transient state are obtained which are compared to get the manual data and test data. The results show that the DGEN380 engine model on steady state is accurate as well as on transition state simulation. The DGEN380 aero engine model built by dynamic equations can simulate steady state and transient state of the engine, which will be applied to design the DGEN380 aero engine controller that implements steady control and transient control function.

\section{Aero Engine Control Problem Statement}

The control system of the DGEN380 aero engine has to ensure optimal production of thrust (power) of the aero 

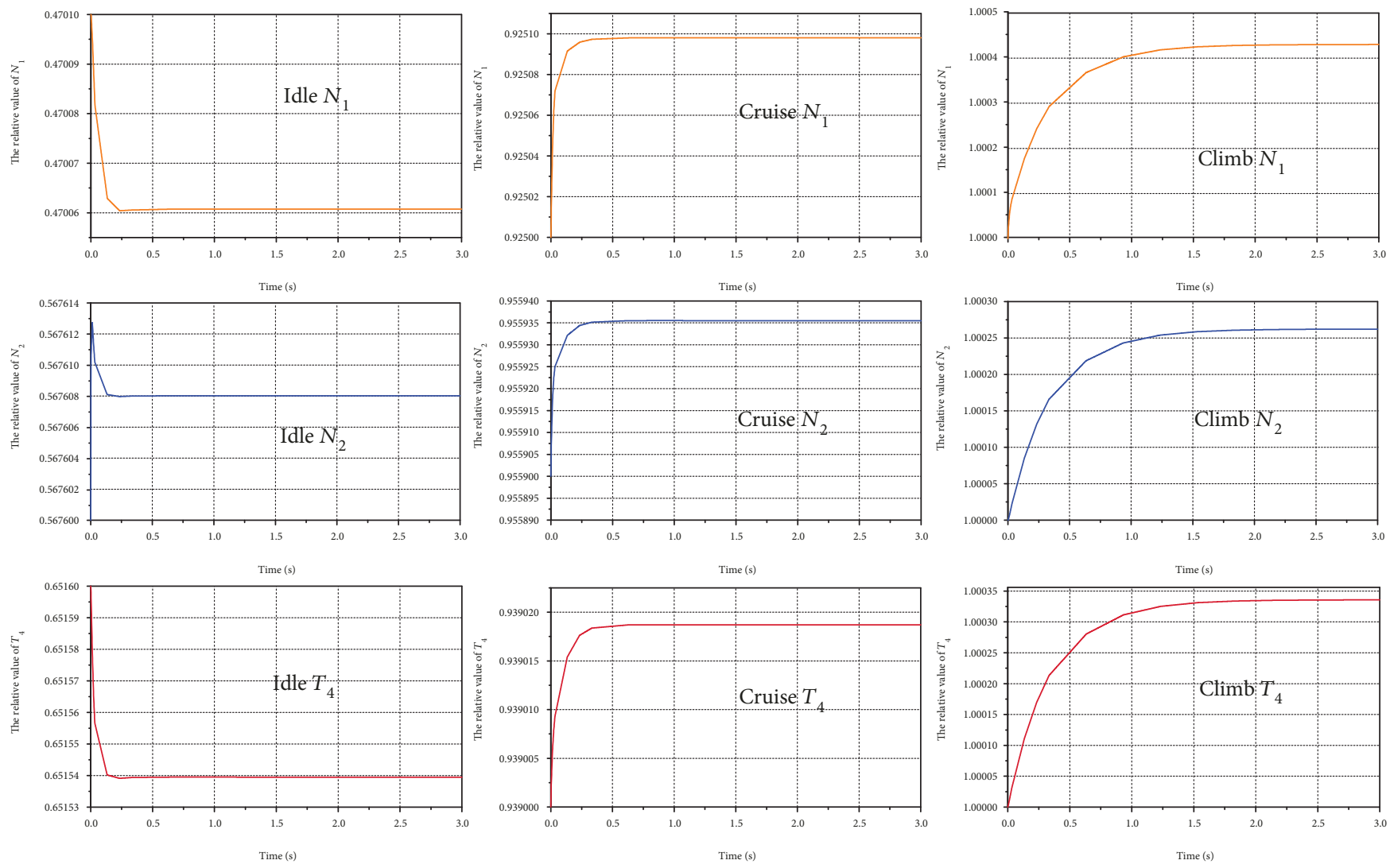

FIgURE 4: Simulation curves of steady state.

engine. The optimal amount of thrust production relies on certain flight conditions that consist of consistent thrust and smooth variation of thrust [7]. That is to say, the primary functions of the aero engine control system are to maintain table thrust levels and maintain repeatable performance during transient operation from one requested thrust level to another. Additionally, the control system should keep stable aerodynamic parameters (temperature or pressure) and rotor speeds within safety limitation and avoid surges and significant speed and aerodynamic parameters variations. So, power management and limitation protection are two essential functions of the control system of the aero engine, while steady state control and transition state control are mainly functions of power management as well as the critical point of this paper.

All say, in essence, the steady state control and the transition state control are the same. The steady state control process keeps the aero engine in maintaining a certain speed of steady state point. Meanwhile, the process of transition state control starts from one steady state point speed to another steady state point speed. They can be expressed as follows:

$$
W_{f}=f_{\text {control }}(\dot{n}, n), \quad \begin{cases}\dot{n}=0, & \text { steady state control } \\ \dot{n} \neq 0, & \text { transition state control. }\end{cases}
$$

So, it is significant to control the low pressure rotor speed of the aero engine, to optimize the aero engine thrust, i.e., control $N_{1}$ to an optimal commanded reference value. The controller is a single controller. Figure 6 shows the control scheme.

\section{Single Controller of Power Management of DGEN380 Aero Engine}

Section 3 has detailed aero engine control problem. The single controller calculates the fuel flow based on the low speed rotor speed and the change rate of low speed rotor speed. A sliding mode control scheme of power management of DGEN380 aero engine is discussed in this section, which also includes the discussion of simulation results. This controller has only one controller unit. To design a robust control algorithm and get the nonlinear dynamics of DGEN380 aero engine, the control approach needs to be built on a sliding mode control method. Since there exists commendation of the sliding mode control method, this strategy has proved its efficiency in different fields of industry, e.g., electrical engineering, energy systems, robot, and aircraft control, broadly.

The core of sliding mode control method is to force the system trajectories to converge to a sliding surface and to be maintained on it in spite of perturbations and uncertainties, thanks to a discontinuous control input. The main features of this class of control are as follows: (1) the input variable is based on the sliding variable which is determined in the control objectives, from the sliding mode, the variable defined the sliding mode surface; (2) the input variable has to force the system trajectories to reach the sliding 


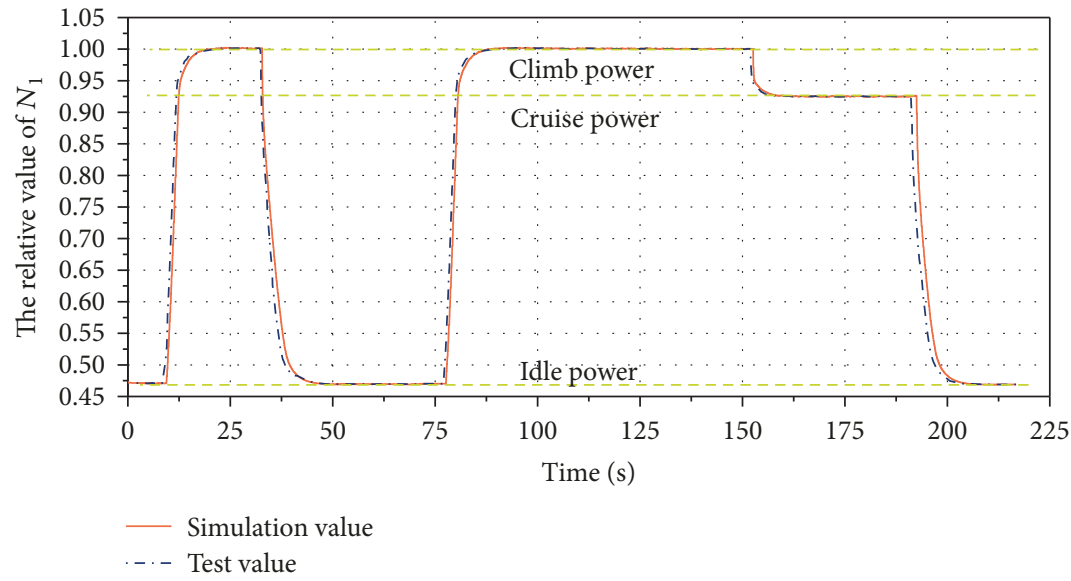

(a)

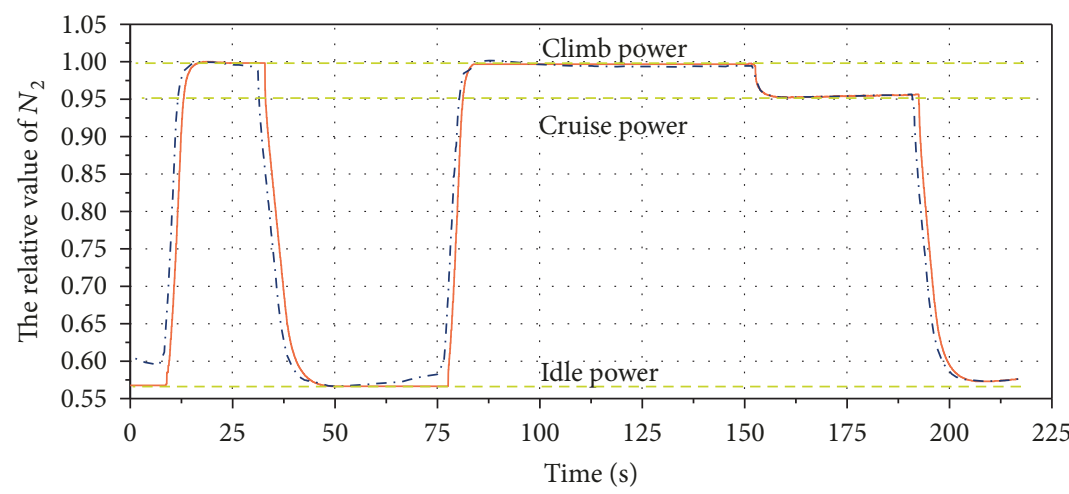

_ Simulation value

...- Test value

(b)

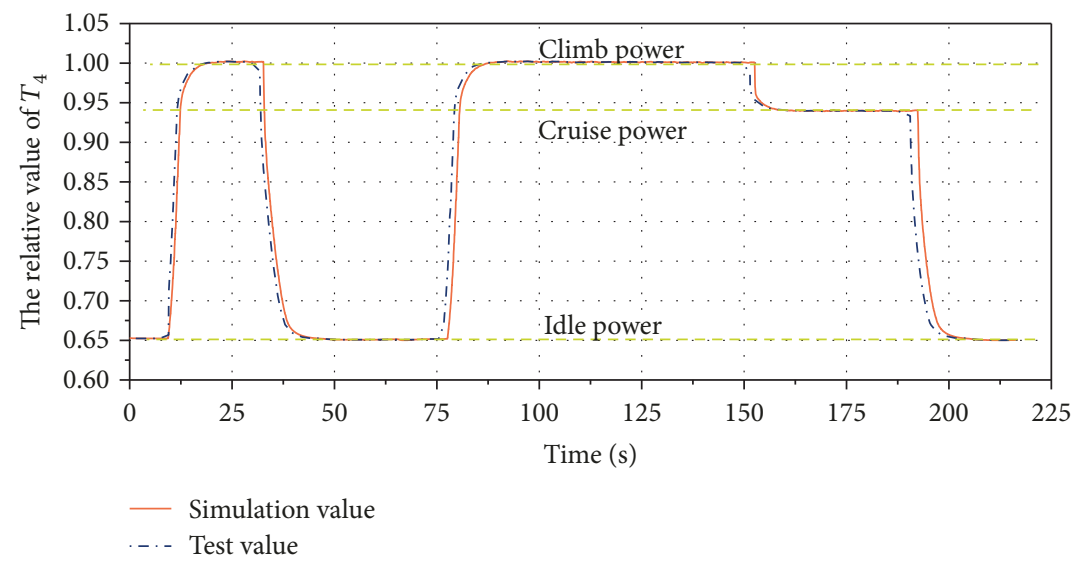

(c)

Figure 5: The results of transition state simulation. (a) Variation curve of $N_{1}$. (b) Variation curve of $N_{2}$. (c) Variation curve of $T_{4}$.

mode surface, in a finite time and spite of the uncertainties and disturbance; and (3) when the sliding mode surface is reached, the trajectories are evolving on it. By this way, the control objectives are fulfilled in spite of uncertainties and disturbance.

4.1. Single Controller Design. The control strategy design is used into the DGEN380 aero engine described in Section 2.
The control approach is calculated from the DGEN380 aero engine nonlinear model given by (5)-(9).

The output vector can be defined as follows:

$$
y=\left[\begin{array}{l}
y_{1} \\
y_{2}
\end{array}\right]=\left[\begin{array}{c}
n_{1}-n_{1, \mathrm{ref}} \\
T_{4}-T_{4, \mathrm{ref}}
\end{array}\right] .
$$




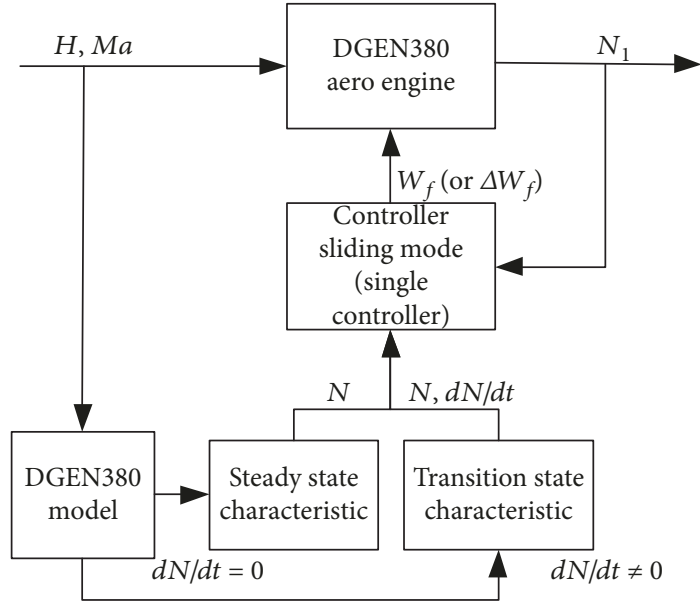

FIGURE 6: Control scheme of power management of DGEN380 aero engine.

TABLE 2: PI controller parameters of the idle power point.

\begin{tabular}{lcc}
\hline Controlled variable & Proportional gain & Integral gain \\
\hline Speed & 29.77 & 5.20 \\
Temperature & 33.09 & 6.55 \\
\hline
\end{tabular}

TABLE 3: Noise characteristics.

\begin{tabular}{lc}
\hline Measured variable & Noise magnitude (\%) \\
\hline Rotor speed & 5 \\
Turbine outlet temperature $T_{4}$ & 4 \\
\hline
\end{tabular}

The control objective is to force $y$ towards a vicinity of zero (in practice). The relative degree vector of systems (5)-(9) with output and versus input is $\left[\begin{array}{ll}1 & 1\end{array}\right]^{T}$.

From the definition of output vector, $y$ can get that the relative degree of each term of the sliding vector has to equal to 1 ; the sliding variable vector is defined as follows:

$$
S=\left[\begin{array}{l}
S_{1} \\
S_{2}
\end{array}\right]=\left[\begin{array}{l}
y_{1} \\
y_{2}
\end{array}\right]
$$

Then, from DGEN380 aero engine model, one gets

$$
\dot{S}=\varphi_{1}(\cdot)+\varphi_{2}(\cdot) \bar{u}
$$

with function $\varphi_{1}(\cdot)$ and $\varphi_{2}(\cdot)$ detailed in (13) and (15). The matrix $\varphi_{2}$ and its nominal value $\varphi_{2 N}$ are invertible.

$\varphi_{1}(\cdot)=\left[\begin{array}{c}\left(\frac{30}{\pi}\right)^{2} \cdot \frac{1}{J_{1}} \cdot \frac{1}{n_{1}} \cdot\left(W_{\mathrm{LPT}} \cdot q_{m, \mathrm{LPT}} \cdot \eta_{l m}-W_{\mathrm{Fan}} \cdot q_{m, \mathrm{Fan}}\right) \\ \frac{R \cdot T_{4} \cdot q_{m, \mathrm{in}}}{C_{V} \cdot P_{4} \cdot V} \cdot\left(C_{p}-C_{V}\right) \cdot\left(T_{3}-T_{4}\right)\end{array}\right]$,

$$
\varphi_{2}(\cdot)=\left[\begin{array}{c}
\left(\frac{30}{\pi}\right)^{2} \cdot \frac{1}{J_{1}} \cdot \frac{1}{n_{1}} \cdot W_{\mathrm{LPT}} \cdot \eta_{l m} \\
\frac{R \cdot T_{4}}{C_{V} \cdot P_{4} \cdot V} \cdot\left(C_{V}-C_{p}\right) \cdot T_{4}
\end{array}\right]
$$

Each parameter can be written as the equation that a nominal part plus an uncertain one equals the parameters. And both $\varphi_{1}$ and $\varphi_{2}$ can be expressed by a similar way, as a nominal part and an uncertain one,

$$
\begin{aligned}
& \varphi_{1}=\varphi_{1 N}+\Delta \varphi_{1}, \\
& \varphi_{2}=\varphi_{2 N}+\Delta \varphi_{2},
\end{aligned}
$$

where $\varphi_{1 N}$ and $\varphi_{2 N}$ are the nominal parts and $\Delta \varphi_{1}$ and $\Delta \varphi_{2}$ are the uncertain parts.

Assumption 1. The uncertain terms $\Delta \varphi_{1}(x, t)$ and $\Delta \varphi_{2}(x, t)$ are such that $\forall x \in X$ and $t \geq 0$,

$$
\left|\frac{\Delta \varphi_{i}}{\varphi_{i}}\right| \ll 1, \quad(i=1,2) .
$$

Considering the following control law

$$
\bar{u}=\left(\varphi_{2 N}\right)^{-1} \cdot\left(-\varphi_{1 N}+\theta\right)
$$

with $\theta$ regarded as the new control input, one gets

$$
\dot{S}=\left(\Delta \varphi_{1}-\varphi_{2 N}^{-1} \varphi_{1 N} \Delta \varphi_{2}\right)+\left(I_{2 \times 2}+\varphi_{2 N}^{-1} \Delta \varphi_{2}\right) \theta
$$

where $S_{A}=\Delta \varphi_{1}-\varphi_{2 N}^{-1} \varphi_{1 N} \Delta \varphi_{2}$ and $S_{B}=I_{2 \times 2}+\varphi_{2 N}^{-1} \Delta \varphi_{2}$.

It is obvious that the $S_{A}$ and $S_{B}$ are bounded, which means that there exist positive constants $S_{A M}, S_{B m}$, and $S_{B M}$ such that $\forall x \in X$ and $t \geq 0$,

$$
\begin{aligned}
\left|S_{A}\right| & \leq S_{A M}, \\
0 & <S_{B m} \leq\left|S_{B}\right| \leq S_{B M} .
\end{aligned}
$$

The objective $S=0$ in a finite time; despite the uncertain values of $S_{A}$ and $S_{B}$, the control input $\theta$ is based on sliding mode control approach [8] and writes as

$$
\theta=\left[\begin{array}{l}
K_{1} \operatorname{sign}\left(S_{1}\right) \\
K_{2} \operatorname{sign}\left(S_{2}\right)
\end{array}\right],
$$

where $K_{1}$ and $K_{2}$ are gain coefficients of the sliding mode control law. And the $K$ writing as

$$
K>\frac{S_{A M}+\lambda}{S_{B m}},
$$

where $\lambda$ is a positive number, which permits to satisfy the sliding condition $S \dot{S} \leq \lambda|S|$ (that is, $S \dot{S}<0)$, that ensures the finite time convergence of $S$ to 0 . 


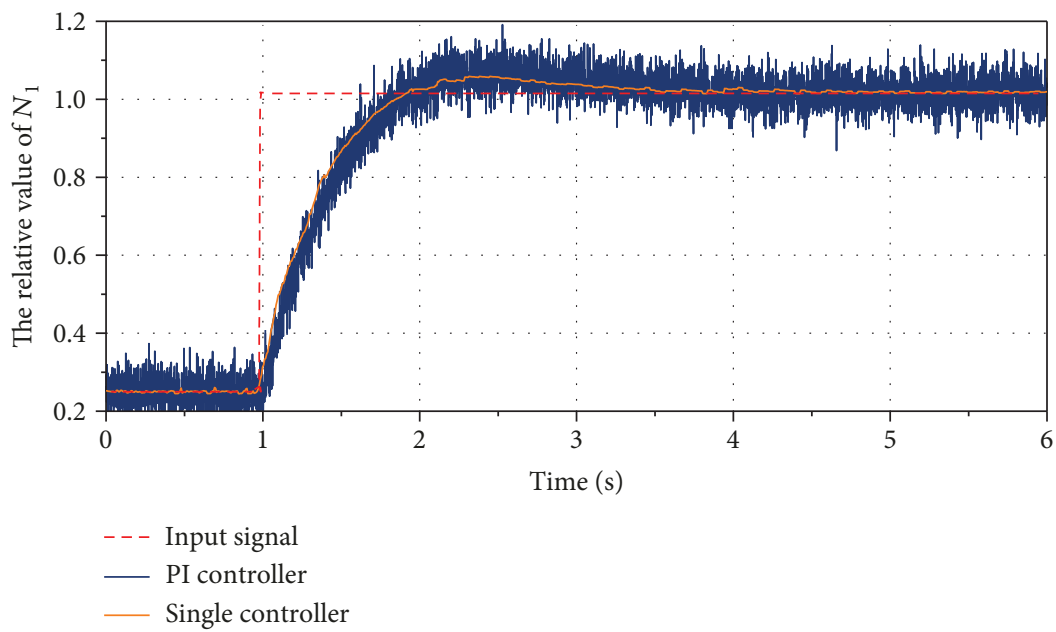

(a)

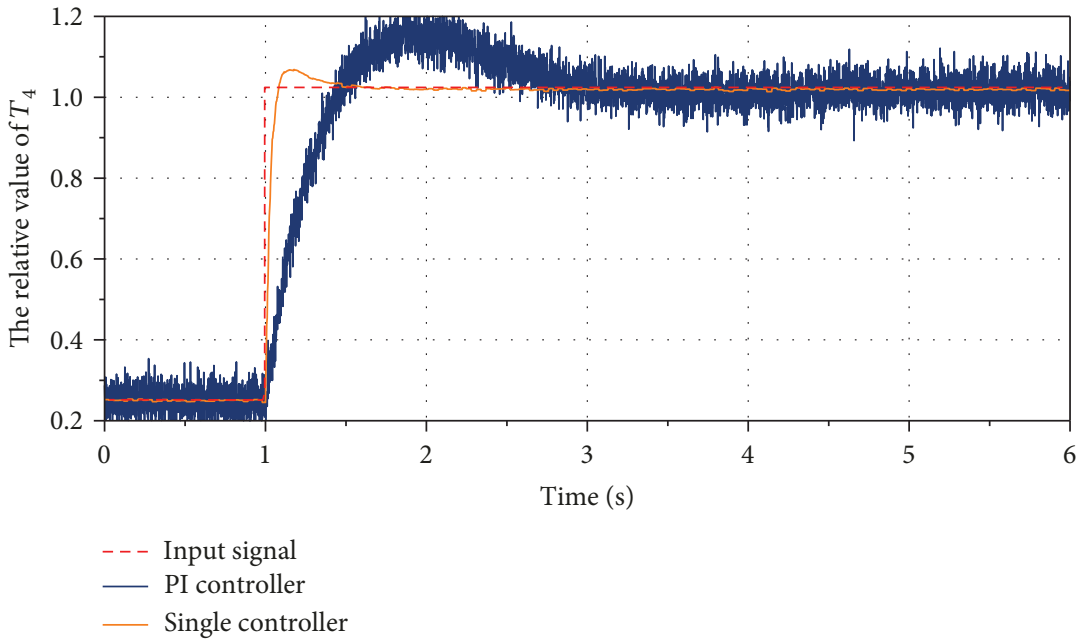

(b)

Figure 7: The simulation results of step response of steady state power management. (a) Low pressure rotor speed $N_{1}$ versus time (s). (b) Turbine outlet temperature versus time (s).

4.2. Discussion of Simulation Results. To evaluate the performance of the single controller of DGEN380 aero engine, the control system of DGEN380 aero engine simulations have to been performed. The power management function of the proposed approach control strategy can be used to maintain table thrust levels (steady state control) and maintain repeatable performance (transition state control). So, the simulations include steady state simulation and transition state simulation.

4.2.1. Steady State Simulation. Steady state simulation focusses on a certain steady state point which concludes fuel step response simulation and harmonic disturbance simulation. The idle power point is selected in the simulation.

The proposed control strategy is comparing with a general PI controller which is applied in aero engine steady state control now, by evaluating different performances such as oscillations and harmonic disturbance of the rotor speed and outlet temperature. The performance of the two controllers can be checked. Meanwhile, the robustness of the two controllers can also be tested.
The PI controller of the idle power point is defined by a general method $[9,10]$, with $\theta$ writing as

$$
\theta=\left[\begin{array}{l}
K_{P 1} S_{1}+K_{I 1} \int_{0}^{t} S_{1}(\tau) d \tau \\
K_{P 2} S_{2}+K_{I 2} \int_{0}^{t} S_{2}(\tau) d \tau
\end{array}\right] .
$$

Table 2 shows the PI parameters of the idle power controller. The PI parameters are computed by Control Toolbox of MATLAB. $S$-function, equations (10) and (11), is regarded as the integral/proportional variable [12].

The harmonic disturbance can be written as

$$
d(t)=0.5 \cos t+\sin 2 t .
$$

A white noise is considered on the main measured variables of control system sensor, such as low pressure rotor speed $N_{1}$, high pressure rotor speed $N_{2}$, and turbine outlet 


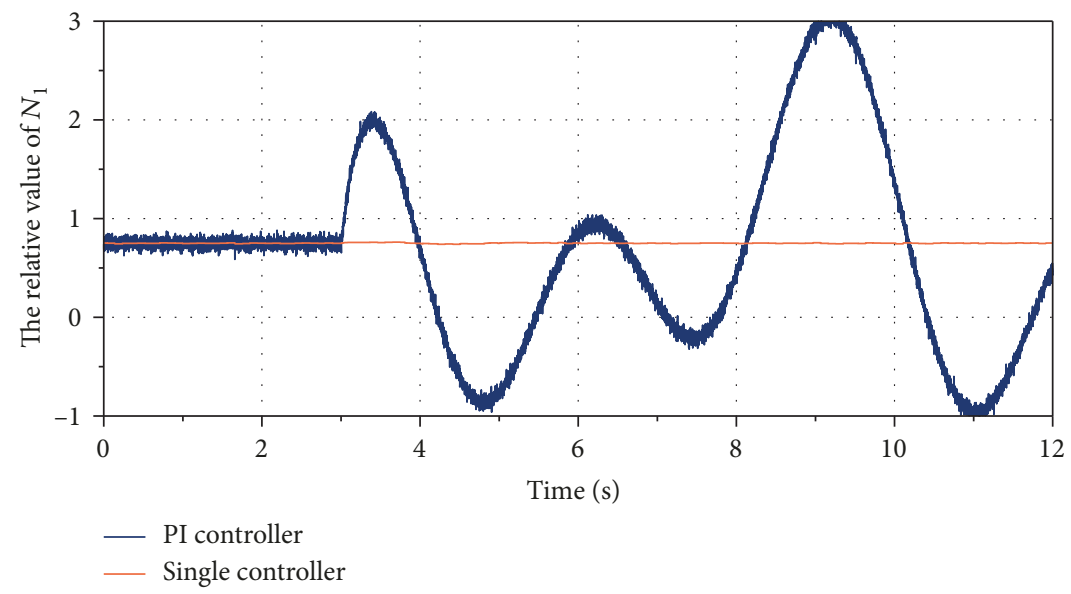

(a)

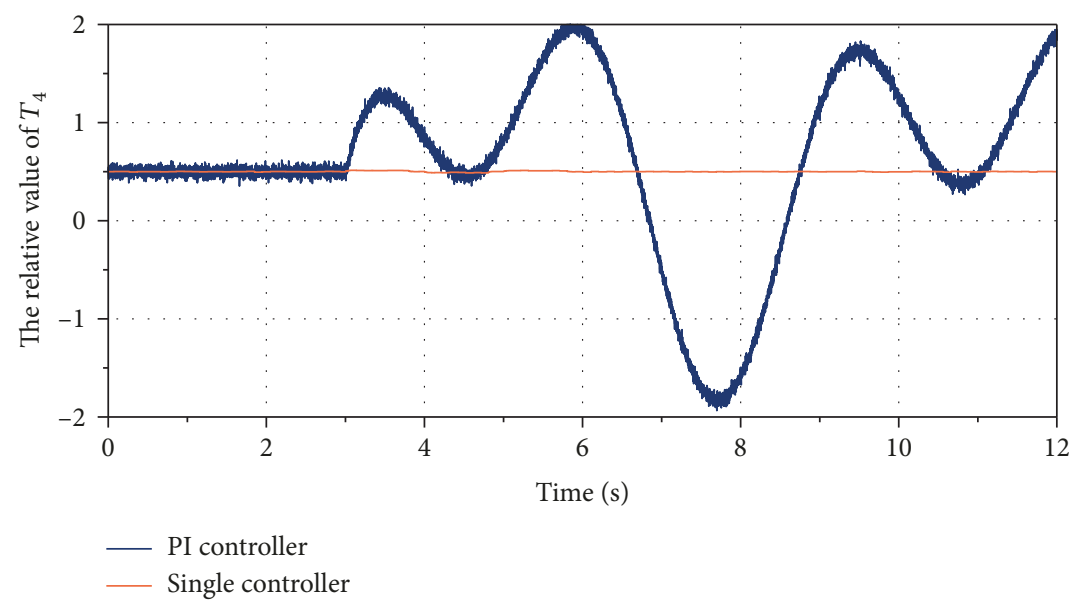

(b)

FIGURE 8: The simulation results of harmonic disturbance of steady state power management. (a) Low pressure rotor speed $N_{1}$ versus time (s). (b) Turbine outlet temperature versus time (s).

temperature $T_{4}$. Table 3 gives the magnitude of the noise. This noise is added to be the output channel.

Figure 7 shows the results of step response when DGEN380 aero engine works in the idle power point. A step signal of fuel is added in the system at 1 second. The white noise is considered. So, the oscillation phenomenon can be observed. Because of the robust sliding mode approach, the oscillation phenomenon of sliding model controller curve and orange curve are fragile-the visible oscillation phenomenon in the PI controller curves.

According to Figure 7, the single controller has the lowest standard deviation of speed and temperature; it induces reduced oscillations. Furthermore, a faster response to output variables is produced with a single controller.

Figure 8 shows the influence of harmonic disturbance (24) on the single controller and PI controller when DGEN380 aero engine works in the idle power point. The harmonic disturbance has a significant impact on the aero engine (and engine control system). So, it is necessary to analyze the influence of the harmonic disturbance which can be applied to test the robustness of the controller. A harmonic disturbance, (24), is added in the system at 3 seconds. The steady state of the aero engine is broken by it. However, the
TABLE 4: PI speed controller parameters.

\begin{tabular}{lcc}
\hline Power point & Proportional gain & Integral gain \\
\hline Idle power & 29.77 & 5.20 \\
Cruise power & 33.52 & 5.58 \\
Climb power & 34.90 & 6.86 \\
\hline
\end{tabular}

PI controller cannot compensate for the influence. The single controller effectively offsets the impact of harmonic disturbance, which reflects the robust of the single controller.

According to the results of the steady state simulations, the single controller is designed by this research which possesses the expected property of steady state control. That is to say, the single controller of DGEN380 aero engine can maintain table thrust levels at a certain steady state point. When the system (control objective) achieves sliding mode surface, sliding function $S$ equals 0 , and the system rests on the sliding mode state, that means the signal noise and harmonic disturbance do not change the state of the system.

4.2.2. Transition State Simulation. Now considering the transient process: the state of aero engine changes from one 


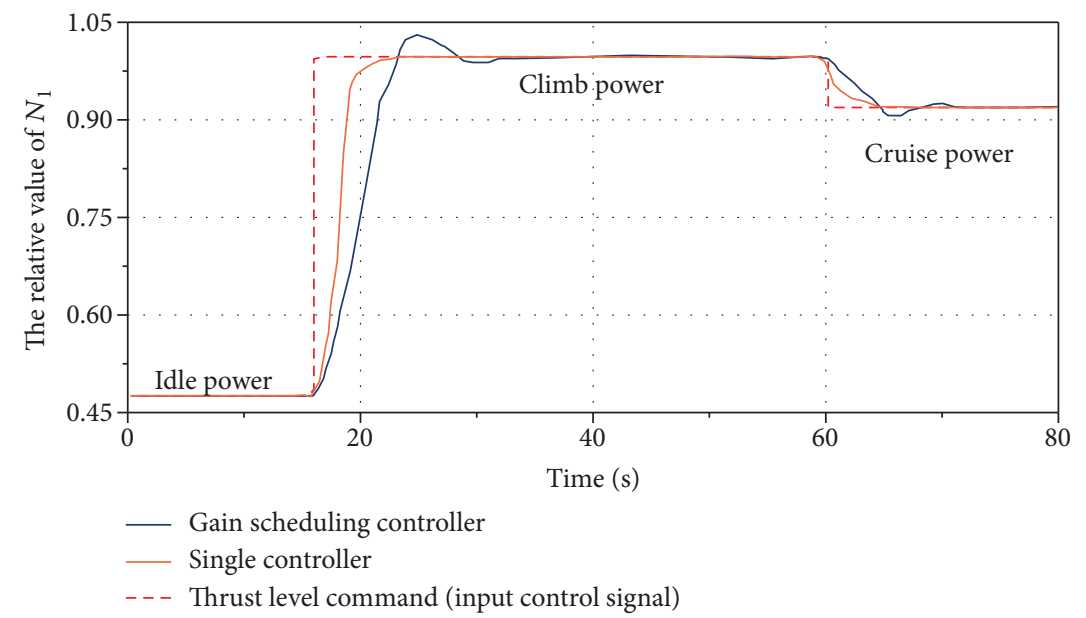

(a)

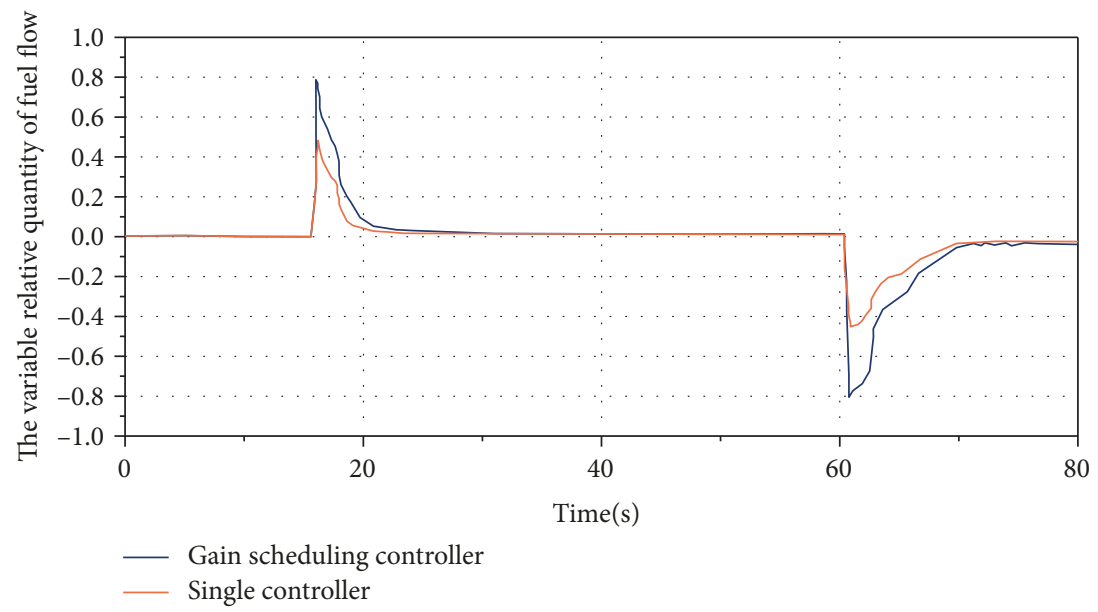

(b)

Figure 9: The simulation results of transition state power management. (a) Low pressure rotor speed $N_{1}$ versus time (s). (b) Variable relative quantity of fuel flow versus time (s).

requested thrust level to another, the controller should maintain repeatable performance during this transient operation. Then, the idle power state, cruise power state, and climb power state are selected for simulation. The following scenario is assumed: DGEN380 aero engine implements acceleration from the idle power point to the climb power point; then, it decelerated back to cruise power point. And low pressure speed is selected as the output variable.

The proposed approach control strategy is compared with a gain scheduling approach based on a multi-PI controller that is applied in aero engine transient control now. PI controller only calculates the steady state performance of the aero engine. However, the transient control focuses on at least two steady state points. The gain scheduling approach is applied in actual aero engine control now which switches the corresponding PI controller based on aero engine performance. Table 4 shows the PI parameters of three state power speed controllers $[11,12]$. The PI parameters are computed by Control Toolbox of MATLAB.

In concluding that the single controller can compensate for the influence of signal noise, the harmonic disturbance is obtained in Section 4.2.1, then the transition state simula- tion will ignore the impact of signal noise and harmonic disturbance.

Figure 9 shows the transition simulation results. Significant improvements in the performance during DGEN380 aero engine in acceleration and deceleration stages can be seen in Figure 9. From $t=16 \mathrm{~s}$, the state changes from the idle power to the climb power which is the acceleration process. And from $t=60 \mathrm{~s}$, the state changes from the climb power to the cruise power, that is deceleration process. In other words, the two thrust lever commands are added in the system at $t=16 \mathrm{~s}$ and $t=60 \mathrm{~s}$. However, the gain scheduling controller has overshoot in transient control, and the response is slower than the sliding model controller. What is more, the single controller calculates fewer fuel to implement transient control (Figure 9(b)).

According to the results of the transition state simulations, the single controller designed by this research possesses the anticipate behavior of transition state control. That is to say, the sliding mode controller of DGEN380 aero engine can maintain repeatable performance during the transient process. The nonlinear controller, single controller, can realize the transient control function. Meanwhile, the specific 


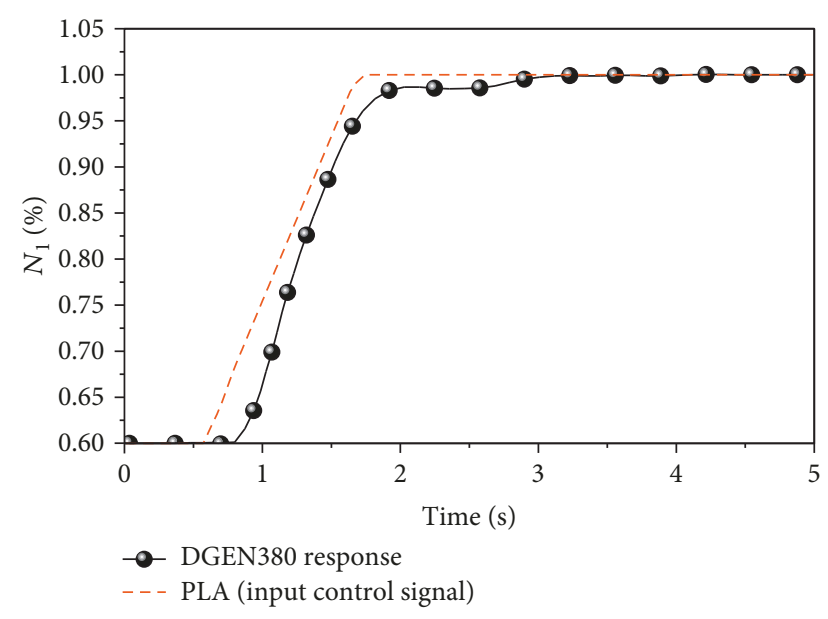

FIgURE 10: The test of single controller.

fuel consumption of this control approach is lower than that of the traditional approach which gains scheduling when the system state changes from one state to another.

4.3. Discussion of Experimental Results. The performance of the single controller can be obtained by simulation in Section 4.2. However, this single controller has been conducted in a simulation environment. Aero engine experiment is necessary, which could reveal the performance of the controller for real-world conditions.

The single controller will be tested in DGEN380 aero engine test bench (Figure 2) which enables aero engine technology studies on a relevant platform and moves beyond the typical simulation system studies. The detailed description of this test bench may be referred to [13]. The single controller is used for DGEN380 aero engine. The code of the single controller is written in the engine control unit of FADEC PC.

The test bench aero engine is run at a cruise condition of $10,000 \mathrm{ft}$ and Mach 0.33 . The single controller is conducted. To ensure that the single controller as applied to the real aero engine meets the control system requirement, a PLA command at the 0.6-second mark from $43 \%$ PLA power (idle power) to $47 \%$ PLA power (climb power) is shown in Figure 10. All of the values shown are normalized such that zero represents a cruise condition (43\% PLA power) and one is at $47 \%$ PLA power. Here, the response of the engine controller can meet the requirement within aero engine control.

\section{Conclusion}

A new configuration of the small aero engine, DGEN380 aero engine, has been presented in this research. A nonlinear dynamic model of DGEN380 aero engine has been built by rotor dynamic equations and volume dynamic equations. Meanwhile, the sliding mode control method has been developed, which is an advanced nonlinear control approach. A single controller based on sliding mode control method has been designed with the objective to keep table thrust levels during steady state and maintain repeatable performance during transient operation from one requested thrust level to another. The proposed control scheme is compared to a general PI controller or multi-PI controllers (gain scheduling approach). Because of the robustness of the single controller designed by this paper, the controller can offset the impact of the signal noise and harmonic disturbance at a certain power point. And the dynamic performance of the single controller is satisfactory at the transient process. Meanwhile, the single controller calculates fewer fuel flow. These performances are explained by computer simulation. The single controller has been examined in the aero engine test bench. The experimental results depicted good performance.

\section{Data Availability}

The data used to support the findings of this study are available from the corresponding author upon request.

\section{Conflicts of Interest}

The authors declare that they have no conflicts of interest.

\section{References}

[1] J. W. Connolly, J. Csank, A. Chicatelli, and K. Franco, "Propulsion controls modeling for a small turbofan engine," in 53rd AIAA/SAE/ASEE Joint Propulsion Conference, Atlanta, GA, USA, July 2017.

[2] X. Liu and Y. Yuan, "Nonlinear system modeling and application based on system equilibrium manifold and expansion model," Journal of Computational and Nonlinear Dynamics, vol. 9, no. 2, article 021013, 2014.

[3] I. Guenoune, "Modeling and robust control of a twin wind turbines structure," Control engineering practice, vol. 69, no. 69, pp. 23-35, 2017.

[4] L. Rodriguez and R. Botez, "Generic New Modelling Technique for Turbofan Engines Thrust," in AIAA Modeling and Simulation Technologies Conference, Minneapolis, MN, USA, August 2012.

[5] A. P. Wiese, M. J. Blom, M. J. Brear, C. Manzie, and A. Kitchener, "Development and validation of a physics-based, dynamic model of a gas turbine," in Volume 4: Ceramics; Concentrating Solar Power Plants; Controls, Diagnostics and Instrumentation; Education; Electric Power; Fans and Blowers, San Antonio, TX, USA, June 2013.

[6] K. Lee, M. Wilson, and M. Vahdati, "Validation of a numerical model for predicting stalled flows in a low-speed fan-part I: modification of Spalart-Allmaras turbulence model," Journal of Turbomachinery, vol. 140, no. 5, article 051008, 2018.

[7] L. Peng and K. Mohseni, "Nonlinear dimensionality reduction for parameterized partial differential equation," in 43rd Fluid Dynamics Conference, San Diego, CA, USA, June 2013.

[8] S. Victor, A. Taymans, and P. Melchior, "Robust control system design of a turbofan," in IFAC International Conference on Fractional Differentiation and Its Applications, Novi Sad, Republic of Serbia, July 2016.

[9] A. Uehara, A. Pratap, T. Goya et al., "A coordinated control method to smooth wind power fluctuations of a PMSGbased WECS," Ieee Transactions on Energy Conversion, vol. 26, no. 2, pp. 550-558, 2011.

[10] O. E. Adetifa, A. McAlpine, and G. Gabard, "Nonlinear propagation of supersonic fan tones in turbofan intake ducts," AIAA Journal, vol. 56, no. 1, pp. 316-328, 2018. 
[11] D. Mortari, H. R. Johnston, and L. I. Smith, "Least-squares solutions of nonlinear differential equations," in 2018 Space Flight Mechanics Meeting, Kissimmee, FL, USA, January 2018.

[12] A. Zandi Nia and R. Nagamune, "Switching gain-scheduled proportional-integral-derivative electronic throttle control for automotive engines," Journal of Dynamic Systems, Measurement, and Control, vol. 140, no. 7, article 071015, 2018.

[13] "Price Induction DGEN Engine Specifications," December 2015, http://www.price-induction.com/dgen-engine/. 


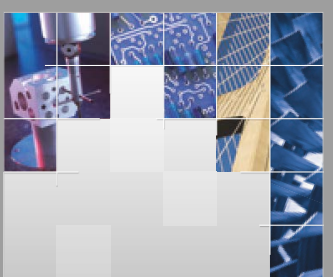

\section{Enfincering}
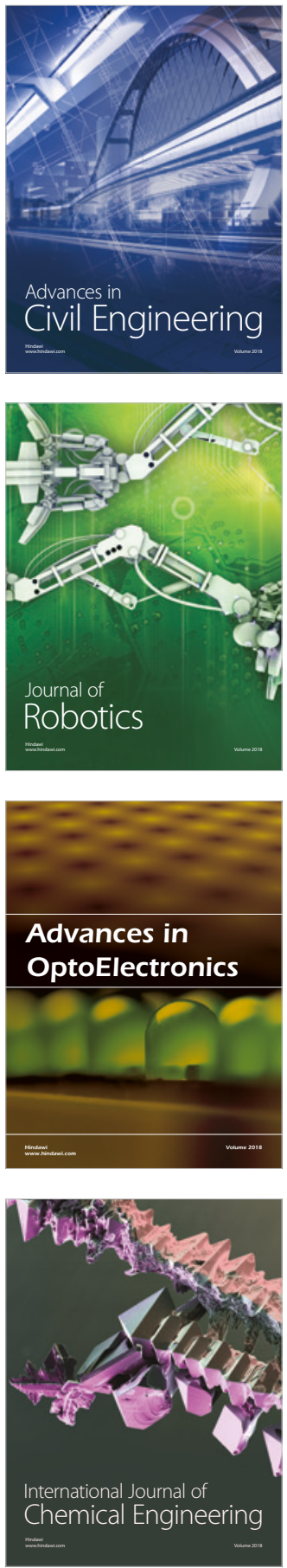

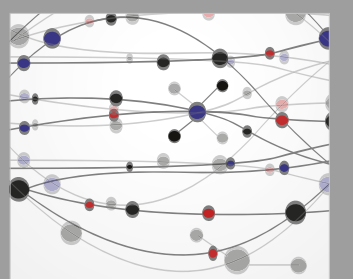

\section{Rotating \\ Machinery}

The Scientific World Journal

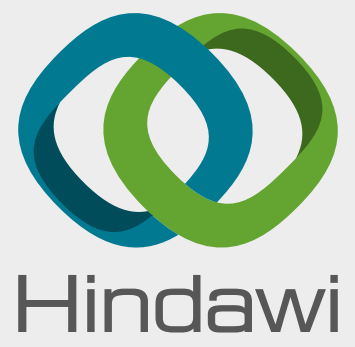

Submit your manuscripts at

www.hindawi.com
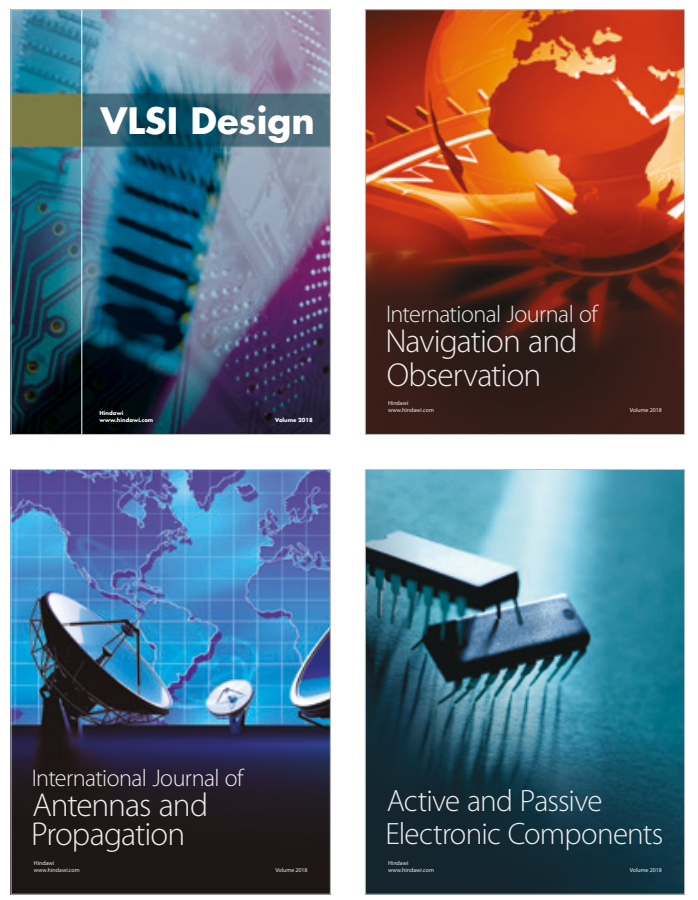
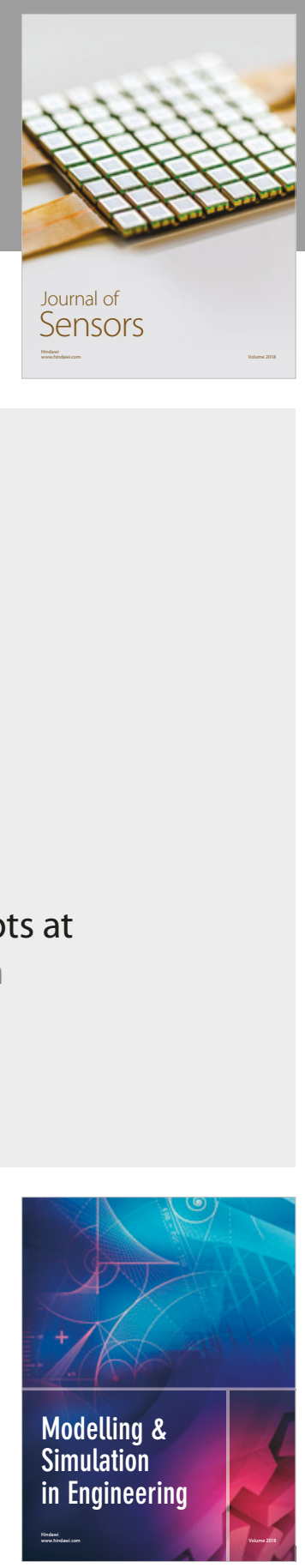

\section{Advances \\ Multimedia}
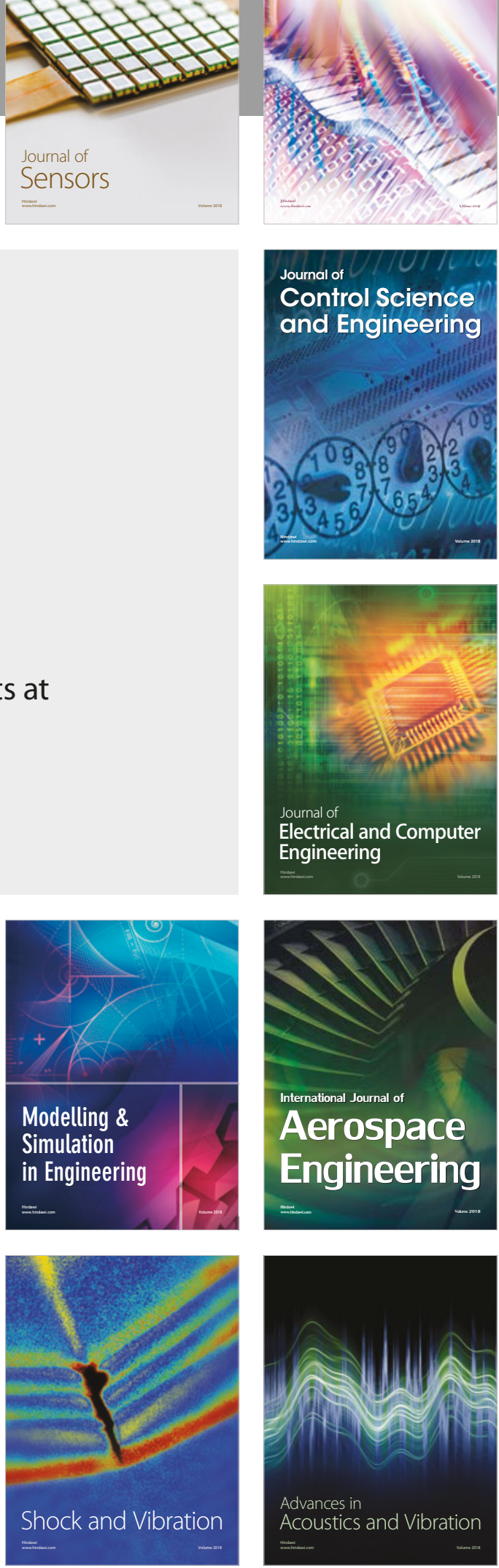